\title{
Long-term survival in lung transplant recipients after successful preoperative coronary revascularization
}

\author{
Leonardo Seoane, MD, Lee M. Arcement, MD, Vincent G. Valentine, MD, and P. Michael McFadden, MD
}

From the Ochsner Multi-Organ Transplant Center, Section of Pulmonary and Critical Care Medicine, Division of Cardiothoracic Surgery, Department of Surgery, Ochsner Clinic Foundation, New Orleans, La.

Received for publication Oct 26, 2004; revisions received Dec 15, 2004; accepted for publication Dec 20, 2004.

Address for reprints: Leonardo Seoane, MD, Ochsner Clinic Foundation, 1514 Jefferson Highway, New Orleans, LA 70121 (E-mail: lseoane@ochsner.org).

J Thorac Cardiovasc Surg 2005;130:538-41 $0022-5223 / \$ 30.00$

Copyright $\odot 2005$ by The American Association for Thoracic Surgery

doi:10.1016/j.jtcvs.2004.12.017
Objective: Coronary artery disease is considered a contraindication to lung transplantation. We studied effect of pre-lung transplantation nonobstructive coronary artery disease and revascularized coronary artery disease on long-term lung transplant survival.

Methods: Clinical courses of 172 lung transplant recipients from December 1990 to May 2003 were reviewed. Significant coronary artery disease, defined as left main stenosis of greater than $50 \%$ or other epicardial vessel stenosis of greater than $70 \%$, was present in 7 patients; 6 received percutaneous coronary intervention and 1 received coronary artery bypass grafting before transplantation.

Results: Groups were similar with regard to sex, race, or length of intensive care days. The group with normal coronary arteries was significantly younger than the groups with coronary artery disease. The revascularized group had a significant increase in dysrhythmias $(P<.003)$ and 1-, 3-, and 5-year survivals of 85\%, 85\%, and $69 \%$, respectively. Those with insignificant coronary artery disease (14 patients) demonstrated a 1-, 3-, and 5-year survival of $64 \%, 40 \%$, and $32 \%$, respectively. The normal coronary group (151 patients) had a 1-, 3-, and 5-year survival of 75\%, 58\%, and $40 \%$, respectively. The revascularized group had a significant survival advantage compared with that of the insignificant coronary artery disease group $(P<.04$, log-rank test).

Conclusion: Long-term survival of lung transplant recipients with revascularized coronary arteries is similar to that of subjects with normal coronary arteries, despite an increased incidence of dysrhythmias. Lung transplant recipients with insignificant coronary artery disease had a worse survival than the revascularized group. More studies are needed to ascertain the cause and determine the optimal management for lung transplant recipients with insignificant coronary artery disease.

$\mathrm{S}$ ignificant coronary artery disease (CAD) has traditionally been considered a contraindication to lung transplantation. ${ }^{1}$ A recent survey of North American lung transplantation centers demonstrated that most programs still considered $\mathrm{CAD}$ an absolute or relative contraindication for lung transplantation. ${ }^{2}$ Because of shared risk factors between chronic lung disease and CAD, patients considered for lung transplantation often have concurrent $\mathrm{CAD}^{3-5}$ Snell and colleagues ${ }^{5}$ have reported a CAD prevalence of $17 \%$ among patients older than 50 years who received an angiogram during their workup for lung transplantation. The dearth of available donor lungs and suspected poor outcomes have led most lung transplantation centers to turn down candidates with CAD for lung transplantation. ${ }^{1,2}$ Data from the International Society for Heart and Lung Transplantation registry demonstrating a $5 \%$ annual mortality in lung allograft recipients (LARs) caused by $\mathrm{CAD}^{6}$ and evidence that renal allograft recipients have a worse outcome in the setting of preoperative $\mathrm{CAD}^{7}$ provide indirect support of this practice habit. Furthermore, there is the concern that chronic immunosuppression, the metabolic consequences of 
TABLE 1. Demographics for the 3 lung transplant groups (n $=172$ )

\begin{tabular}{lcccc}
\hline & $\begin{array}{c}\text { Normal } \\
\text { CAD }\end{array}$ & ISCAD & SCAD & P value \\
\hline No. of patients & 151 & 14 & 7 & \\
Age (y) & $40 \pm 15$ & $57 \pm 6$ & $59 \pm 6$ & $<.05$ \\
Male sex & $73(48 \%)$ & $8(57 \%)$ & $4(57 \%)$ & \\
SLTX (\%) & $47(31 \%)$ & $10(71 \%)$ & $6(86 \%)$ & $<.0003$ \\
BLTX (\%) & $104(69 \%)$ & $4(29 \%)$ & $1(14 \%)$ & \\
Diagnosis & & & & \\
$\quad$ Emphysema (\%) & $36(24 \%)$ & $12(86 \%)$ & $3(43 \%)$ & $<.0001$ \\
$\quad$ IPF (\%) & $25(17 \%)$ & $2(14 \%)$ & $2(29 \%)$ & \\
$\quad$ Other (\%) & $90(60 \%)$ & 0 & $2(29 \%)$ & \\
$\quad$ Dysrhythmia (\%) & $27(18 \%)$ & $3(21 \%)$ & $5(71 \%)$ & $<.003$ \\
\hline
\end{tabular}

$C A D$, Coronary artery disease; ISCAD, insignificant coronary artery disease; $S C A D$, significant coronary artery disease; $S L T X$, single lung transplantation; $B L T X$, bilateral lung transplantation; IPF, idiopathic pulmonary fibrosis. *Data are expressed as means $\pm S D$.

the immunosuppressants (ie, diabetes, hypertension, and dyslipidemia), or both may accelerate atherosclerosis. ${ }^{8}$

Several groups have reported case reports or small case series of successful lung transplantation after revascularization either by means of coronary artery bypass grafting $(\mathrm{CABG})$, angioplasty, or angioplasty with stent placement. ${ }^{5,9-13}$ The long-term outcomes of lung transplant recipients with revascularized CAD or the outcomes of lung transplant recipients with insignificant $\mathrm{CAD}$ on preoperative evaluation have not been reported. We sought to determine the importance of pre-lung transplantation nonobstructive $\mathrm{CAD}$ and the role of revascularization of significant CAD (SCAD) on 5-year survival at our center.

\section{Methods}

A retrospective chart review was conducted on the clinical course of all patients who underwent lung transplantation at Ochsner Clinic Foundation between December 1990 and May 2003. All patients were evaluated by using a pretransplantation protocol and had normal left ventricular function. Potential candidates older than 45 years or candidates younger than 45 years with 2 or more risk factors for coronary artery disease were evaluated with a coronary angiogram. Risk factors were defined as male sex, smoking history, hypertension, diabetes, hypercholesterolemia, angina, or history of CAD in a first-degree relative. ${ }^{14}$ Because left-heart catheterization (LHC) is invasive, it was the last test performed in otherwise suitable lung transplantation candidates. LHC was performed through the standard percutaneous femoral approach, and selective angiography was undertaken with multiple cineangiographic views. A significant coronary lesion was defined as a stenosis of greater than $50 \%$ of the left main coronary artery or greater than $70 \%$ of any other epicardial vessel. The insignificant coronary artery disease cohort (ISCAD) was defined as any stenosis not meeting significant criteria. Patients with ISCAD received antihypertensive therapy with angiotensin receptor blockers and hypercholesterol therapy with 3-hydroxy-3-methylglutaryl coenzyme A (HMG-CoA) reductase inhibitors when indicated. Normal LHC was defined as no visualized stenosis. All coronary angiograms were read by the same cardiothoracic surgeon.

Those patients with significant coronary lesions underwent revascularization through percutaneous transluminal angioplasty with stent placement in all amendable lesions before transplantation or CABG before transplantation. The continued patency of arteries subjected to stenting was aided by antiplatelet therapy (aspirin for life and clopidrogel for 3 months). In addition, patients with SCAD received antihypertensive therapy with angiotensin receptor blockers and hypercholesterol therapy with HMG-CoA reductase inhibitors when indicated.

Continuous data were analyzed by using analysis of variance, and categoric data were evaluated by using the Fisher exact test or $\chi^{2}$ test, whichever was appropriate. All tests were 2 tailed. Survival curves were constructed with the Kaplan-Meier method and compared by using log-rank tests. All statistics were performed with SAS version 7.0 software.

\section{Results}

One hundred seventy-two patients underwent transplantation between 1990 and May 2003 at the Ochsner Clinic Foundation. Ninety-nine patients met the criteria for LHC. Of the 73 patients who did not receive LHC, 62 had cystic fibrosis. The remaining 11 patients without cystic fibrosis

TABLE 2. Outcomes for patients with significant coronary artery disease who underwent revascularization

\begin{tabular}{clclll}
\hline Patient no. & \multicolumn{1}{c}{ Coronary artery lesion } & Intervention & Type of LT/CPB & Outcome (d) & Cause of death \\
\hline 1 & $95 \%$ RCA & Stent & LSLTX/no & $2239 /$ deceased & BOS \\
2 & $80 \%$ MID LAD & Stent & LSLTX/no & 1249/deceased & BOS \\
3 & $95 \%$ MID LAD & Stent & LSLTX/no & 2296/deceased & BOS \\
4 & $100 \%$ LAD, 60\% D1 & CABG & RSLTX/yes & $14 /$ deceased & Dysrhythmia \\
5 & $100 \%$ RCA & Stent & RSLTX/no & $1342 /$ alive \\
6 & $90 \%$ OMB, 50\% D1 & Stent & LSLTX/no & 2893/alive \\
7 & $100 \%$ RCA, 30\% LAD, 20\% CX & Stent & BSLTX/no & 1095/alive
\end{tabular}

$L T$, Lung transplantation; $C P B$, cardiopulmonary bypass; $R C A$, right coronary artery; $L S L T X$, left single lung transplantation; $B O S$, bronchiolitis obliterans syndrome; $L A D$, left anterior descending artery; $D 1$, first diagonal branch; $C A B G$, coronary artery bypass graft; $R S L T X$, right single lung transplantation; $O M B$, obtuse marginal branch; $C X$, circumflex coronary artery; $B S L T X$, bilateral sequential lung transplantation. 
TABLE 3. Survival for all groups of patients who underwent revascularization

\begin{tabular}{lccc}
\hline Survival & Normal CAD (\%) & ISCAD (\%) & SCAD (\%) \\
\hline $1 \mathrm{y}$ & 75 & 64 & 85 \\
$3 \mathrm{y}$ & 58 & 40 & 85 \\
$5 \mathrm{y}$ & 40 & 32 & 69 \\
\hline
\end{tabular}

$C A D$, Coronary artery disease; ISCAD, insignificant coronary artery disease; $S C A D$, significant coronary artery disease.

were younger than 40 years. Of those who received LHC, 14 LARs were found to have ISCAD, and 7 had SCAD. The demographics among the groups are shown in Table 1. As expected, LARs without CAD comprised a significantly younger cohort.

Six LARs were treated with percutaneous transluminal coronary angioplasty with stent placement before transplantation and 1 patient underwent single-vessel CABG before transplantation. The outcomes of the 7 patients receiving revascularization are detailed in Table 2. Table 3 shows survival at 1, 3, and 5 years for all 3 groups. Survival in the SCAD group was significantly better than that in the ISCAD group $(P<.04, \log$-rank test; Figure 1$)$. The mean survival among the 3 groups was $3.9 \pm 0.25$ years for those with

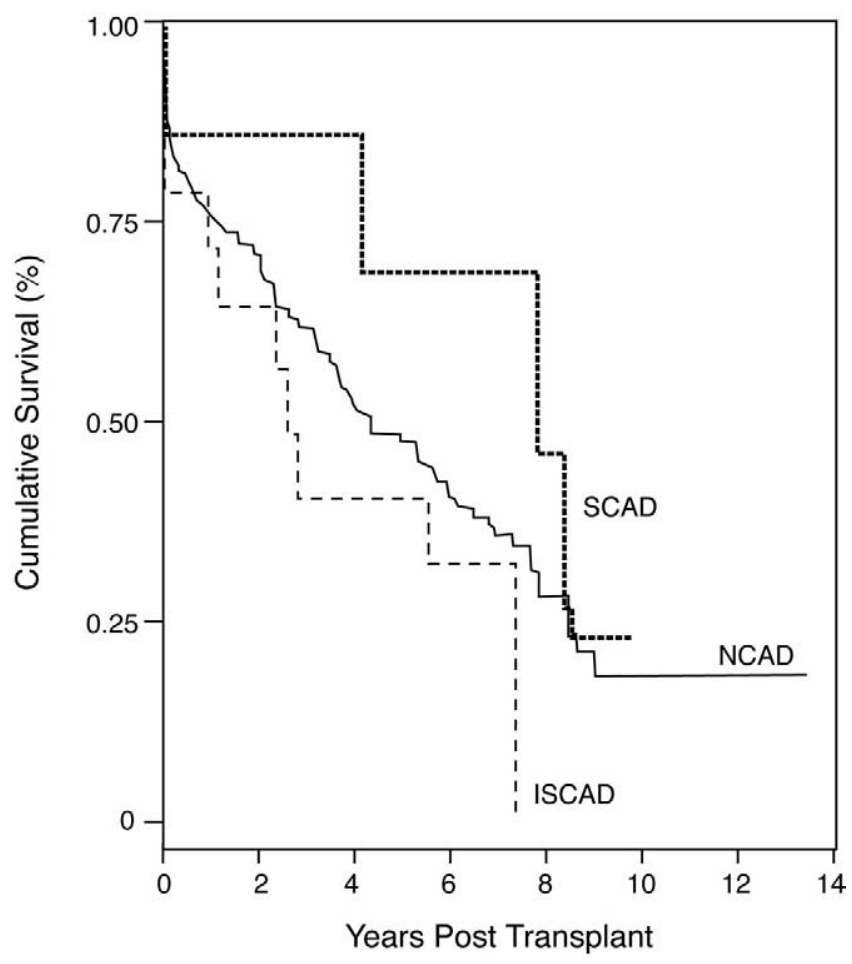

Figure 1. Overall survival for lung transplant recipients with normal coronary arteries (NCAD), insignificant coronary artery disease (ICAD), or revascularized significant coronary artery disease (SCAD).
TABLE 4. Causes of death within the first year after transplantation

\begin{tabular}{|c|c|c|c|}
\hline & $\begin{array}{c}\text { NCAD } \\
(n=151)\end{array}$ & $\begin{array}{c}\text { ISCAD } \\
(n=14)\end{array}$ & $\begin{array}{l}\text { SCAD } \\
(n=7)\end{array}$ \\
\hline Acute graft failure & 4 & 2 & 0 \\
\hline Infection & 19 & 2 & 0 \\
\hline Technical & 7 & 0 & 0 \\
\hline $\begin{array}{l}\text { Multisystem organ } \\
\text { failure }\end{array}$ & 3 & 0 & 0 \\
\hline $\begin{array}{l}\text { Acute coronary } \\
\text { syndrome }\end{array}$ & 0 & 1 & 0 \\
\hline Dysrhythmia & 0 & 0 & 1 \\
\hline
\end{tabular}

$P=$ not significant. NCAD, Normal cardiac arteries; ISCAD, insignificant coronary artery disease; $S C A D$, significant coronary artery disease.

normal cardiac arteries (NCAD), $3.0 \pm 0.7$ years for those with ISCAD, and $5.3 \pm 1$ years for those with SCAD. Table 4 shows the cause of death among the different cohorts. Most of the deaths in the ISCAD group occurred within the first year. One of these deaths was due to an acute coronary syndrome. Bronchiolitis obliterans syndrome was the leading cause of late death in all groups (Table 5). The treatment rates for hypertension and diabetes mellitus were not different among the 3 cohorts (Table 6 ). In addition, the use of statins did not significantly differ among the groups.

\section{Discussion}

CAD is often found among candidates for lung transplantation. ${ }^{3-5}$ The majority of centers still consider CAD to be a relative or absolute contraindication for lung transplantation. $^{2}$ There have been a few reports of successful cases of CABG immediately before lung transplantation with successful outcomes. ${ }^{12,13}$ Several case reports and series have demonstrated revascularization with $\mathrm{CABG}$ at the time of transplantation or with pretransplantation percutaneous coronary intervention, resulting in successful lung transplant outcomes. ${ }^{5,9-11}$ However, no one has reported long-term outcomes. Our study adds to the previous series of successful lung transplantations in patients with CAD amendable to revascularization. In addition, we demonstrate that 5-year

TABLE 5. Causes of death greater than a year after transplantation

\begin{tabular}{lccc}
\hline & $\begin{array}{c}\text { NCAD } \\
(\mathbf{n}=\mathbf{1 5 1})\end{array}$ & $\begin{array}{c}\text { ISCAD } \\
(\mathbf{n}=\mathbf{1 4})\end{array}$ & $\begin{array}{c}\text { SCAD } \\
(\mathbf{n}=\mathbf{7})\end{array}$ \\
\hline $\begin{array}{l}\text { Bronchiolitis obliterans } \\
\quad \text { syndrome }\end{array}$ & 34 & 3 & 3 \\
$\begin{array}{l}\text { Infection } \\
\text { Acute renal failure }\end{array}$ & 14 & 1 & 0 \\
& 1 & 0 & 0
\end{tabular}

$P=$ not significant. NCAD, Normal cardiac arteries; ISCAD, insignificant coronary artery disease; $S C A D$, significant coronary artery disease. 
TABLE 6. Management of cardiovascular related comorbidities

\begin{tabular}{|c|c|c|c|c|c|c|}
\hline & \multicolumn{2}{|c|}{ NCAD $(n=151)$} & \multicolumn{2}{|c|}{ ISCAD $(n=14)$} & \multicolumn{2}{|c|}{$\operatorname{SCAD}(n=7)$} \\
\hline & Pre-Tx & Post-Tx & Pre-Tx & Post-Tx & Pre-Tx & Post-Tx \\
\hline Hypertension & 17 & 97 & 2 & 9 & 2 & 6 \\
\hline $\begin{array}{l}\text { Diabetes } \\
\text { mellitus }\end{array}$ & 12 & 60 & 0 & 3 & 0 & 1 \\
\hline Hyperlipidemia* & 0 & 48 & 3 & 6 & 2 & 4 \\
\hline
\end{tabular}

survival rates are consistent with LARs without CAD at our center.

There are no data on the long-term survival of LARs after coronary revascularization. Our data demonstrate that long-term survival among the SCAD group is comparable with that of LARs with normal coronary arteries, despite the former consisting of an older cohort and more single-lung transplantations and being associated with more dysrhythmias. Interestingly, we found worse outcomes among the LARs with ISCAD. The worse outcomes for LARs with ISCAD suggest that these coronary lesions might pose a problem after lung transplantation. One explanation is that the immunosuppressants themselves, the metabolic consequences of the immunosuppressants (eg, diabetes mellitus, hypertension, and hypercholesterolemia), or both might accelerate atherosclerotic vascular disease after transplantation. However, most of the deaths in the ISCAD group occurred early within the first year. These early deaths might have occurred by chance because of the small number of cases. However, we cannot rule out the possibility of these early deaths being related to these presumed insignificant coronary lesions. Further studies are needed to elucidate whether there is a true association between ISCAD and worse outcomes after lung transplantation.

Our study is limited by its retrospective design. In addition, it is a single-center study consisting of few subjects in 2 of the cohorts. However, these favorable short-term outcomes are consistent with previously published series. Repeated favorable long-term outcomes observed by other groups would confirm the utility of CAD revascularization for lung transplantation candidates with correctable CAD.

In conclusion, coronary revascularization for SCAD might allow individuals with correctable $\mathrm{CAD}$ to safely undergo lung transplantation and have successful long-term outcomes. The optimal method of revascularization depends on the expertise of the institution. ISCAD might not be so insignificant for LARs. Further studies are needed to elucidate the reasons for these worse outcomes and to improve the medical management.

\section{References}

1. Maurer JR, Frost AE, Estenne M, Higenbottam T, Glanville AR. International guidelines for the selection of lung transplant candidates. The International Society for Heart and Lung Transplantation, the American Thoracic Society, the American Society of Transplant Physicians, the European Respiratory Society. J Heart Lung Transplant. 1998; 17:703-9.

2. Levine SM, Transplant/Immunology Network of the American College of Chest Physicians. A survey of clinical practice of lung transplantation in North America. Chest. 2004;125:1224-38.

3. Thaik CM, Semigran MJ, Ginns L, Wain JC, Dec GW. Evaluation of ischemic heart disease in potential lung transplant recipients. J Heart Lung Transplant. 1995;14:257-66.

4. Leibowitz DW, Caputo AL, Shapiro GC, Schulman LL, McGregor CC, Di Tullio MR, et al. Coronary angiography in smokers undergoing evaluation for lung transplantation: is routine use justified? J Heart Lung Transplant. 1994;13:701-3.

5. Snell GI, Richardson M, Griffiths AP, Williams TJ, Esmore DS. Coronary artery disease in potential lung transplant recipients $>50$ years old: the role of coronary intervention. Chest. 1999;116:874-9.

6. Bennett LE, Keck BM, Hertz MI, Trulock EP, Taylor DO. World wide thoracic organ transplantation: a report from the UNOS/ISHLT international registry for thoracic organ transplantation. Clin Transplant. 2001;25-40.

7. Braun WE, Marwick TH. Coronary artery disease in renal transplant recipients. Cleve Clin J Med. 1994;61:370-85.

8. Arcement LM, Dhillon, GS, Knower MT, Kantrow SP, Valentine VG. Metabolic consequences of lung transplantation [abstract]. Am J Respir Crit Care Med. 1999;159:A276.

9. Patel VS, Messier RH, Palmer SM, Davis RD. Coronary artery revascularization in eligible lung transplant recipients. J Heart Lung Transplant. 2001;20:223.

10. Patel VS, Palmer SM, Messier RH, Davis RD. Clinical outcome after coronary artery revascularization and lung transplantation. Ann Thorac Surg. 2003;75:372-7.

11. La Francesca S, Shennib H. Coronary artery revascularization followed by single-lung transplantation in a patient with combined endstage idiopathic pulmonary fibrosis and left main coronary artery stenosis. Tex Heart Inst J. 1995;22:189-91.

12. Khatchatourian G, Chevalley C, Spiliopoulos A, Licker M. Myocardial revascularization and bilateral lung transplantation without cardiopulmonary bypass. Eur J Cardiothorac Surg. 2001;20:1042-4.

13. Kaza AK, Dietz JF, Kern JA, Jones DR, Robbins MK, Fiser SM, et al. Coronary risk stratification in patients with end-stage lung disease. J Heart Lung Transplant. 2002;21:334-9.

14. Pearson TA, Blair SN, Daniels SR, Eckel RH, Fair JM, Fortmann SP, et al. AHA Guidelines for Primary Prevention of Cardiovascular Disease and Stroke: 2002 Update: Consensus Panel Guide to Comprehensive Risk Reduction for Adult Patients Without Coronary or Other Atherosclerotic Vascular Diseases. American Heart Association Science Advisory and Coordinating Committee. Circulation. 2002;106: 388-91. 